Received: 24 May 2017

Accepted: 1 December 2017

Published online: 12 December 2017

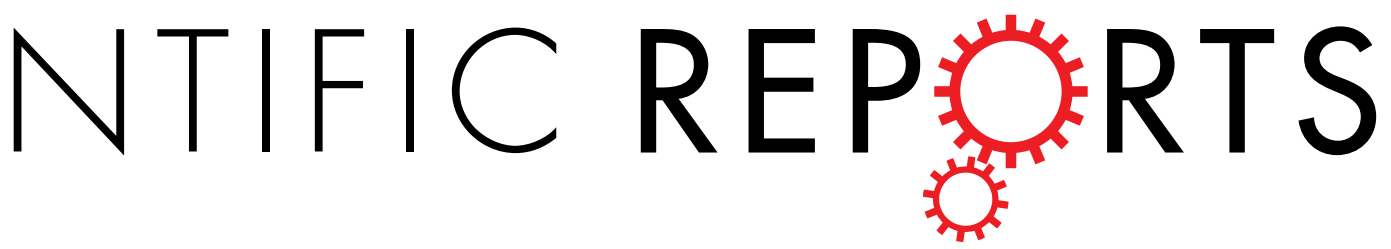

\title{
Effect of high-power-laser with and without graphite coating on bonding of resin cement to lithium disilicate ceramic
}

\author{
Fernanda A. Feitosa ${ }^{1}$, Rodrigo M. de Araújo² ${ }^{2}$ Franklin R. Tay ${ }^{3}$, Lina Niu ${ }^{4}$ \& César R. Pucci ${ }^{1}$
}

The present study evaluated the effect of different high-power-laser surface treatments on the bond strength between resin cement and disilicate ceramic. Lithium disilicate ceramic specimens with truncated cones shape were prepared and divided into 5 groups: HF (hydrofluoric acid-etching), Er:YAG laser + HF, Graphite + Er:YAG laser + HF, Nd:YAG laser + HF, and Graphite + Nd:YAG laser + HF. The treated ceramic surfaces were characterized with scanning electron microscopy and surface roughness measurement. Hourglasses-shaped ceramic- resin bond specimens were prepared, thermomechanically cycled and stressed to failure under tension. The results showed that for both the factors "laser" and "graphite", statistically significant differences were observed $(p<0.05)$. Multiple-comparison tests performed on the "laser" factor were in the order: Er:YAG $>$ Nd:YAG $(p<0.05)$, and on the "graphite" factor were in the order: graphite coating $<$ without coating $(p<0.05)$. The Dunnett test showed that Er:YAG + HF had significantly higher tensile strength $(p=0.00)$. Higher surface roughness was achieved after Er:YAG laser treatment. Thus Er:YAG laser treatment produces higher bond strength to resin cement than other surface treatment protocols. Surface-coating with graphite does not improve bonding of the laser-treated lithium disilicate ceramic to resin cement.

There is an increasing trend for lithium disilicate ceramic to be used in restorative dentistry because of the esthetic values and high flexural strengths achieved by those restorations ${ }^{1,2}$. Different surface treatment techniques are used to enhance the bond strength between silicate-based ceramics and resin cements ${ }^{3-5}$. Hydrofluoric acid (HF)-etching is the most commonly used for conditioning silicate-based ceramic surfaces. Recent studies indicate that high-energy lasers such as Er:YAG (erbium-doped: yttrium aluminum garnet) and Nd:YAG (neodymium-doped: YAG) lasers further improve resin-ceramic bonding when laser treatment is used in conjunction with HF-etching. The Er:YAG laser removes surface particles by "ablation", that involves micro-explosions and vaporization ${ }^{6,7}$. The Nd:YAG laser increases surface roughness to create better adhesion between the resin and ceramic surface ${ }^{8,9}$.

Laser irradiation creates micro-retentions that enhance the surface energy of the ceramic and facilitate silane application, resulting in more durable resin-ceramic bonding. This effect is related to pigmentation of the substrate and the amount of water it contains. Since, the ceramic substrate is almost water-free and its color is opaque white, a problem related to laser treatment is that the ceramic surface may not absorb the emitted energy sufficiently, thereby reducing the intended effects. Thus, a coating on the ceramic surface has been suggested as a means to increase laser energy absorption ${ }^{10-13}$. Graphite coating is often chosen for its high absorptivity qualities, ease of application, availability and also for economic reasons ${ }^{10-13}$.

Progress in adhesive dentistry has led to the development of different mechanical testing approaches to measure the bond strength between ceramic and resin cements. These approaches include tensile, microtensile, shear

\footnotetext{
${ }^{1}$ Department of Restorative Dentistry, Institute of Science and Technology, São Paulo State University UNESP São Jose dos Campos, São Paulo, Brazil. ${ }^{2}$ Department of Dental Materials and Prosthodontics, Institute of Science and Technology, São Paulo State University UNESP São Jose dos Campos, São Paulo, Brazil. ${ }^{3}$ The Dental College of Georgia, Augusta University, Augusta, GA, USA. ${ }^{4}$ State Key Laboratory of Military Stomatology \& National Clinical Research Center for Oral Diseases \& Shaanxi Key Laboratory of Oral Diseases, Department of Prosthodontics, School of Stomatology, The Fourth Military Medical University, Xi'an, Shaanxi, China. Correspondence and requests for materials should be addressed to L.N. (email: niulina831013@126.com) or C.R.P. (email: cesar@fosjc.unesp.br)
} 


\begin{tabular}{|l|l|l|l|}
\hline Brand names & Manufacturer & Chemical composition & Batch number \\
\hline IPS e.max Press-LTD3 & $\begin{array}{l}\text { Ivoclar-Vivadent, Schaan, } \\
\text { Liechtenstein }\end{array}$ & $\begin{array}{l}\mathrm{SiO}_{2}, \mathrm{Li}_{2} \mathrm{O}, \mathrm{K}_{2} \mathrm{O}, \mathrm{MgO}, \mathrm{ZnO}, \mathrm{Al}_{2} \mathrm{O}_{3}, \mathrm{P}_{2} \mathrm{O}_{5} \text { and other } \\
\text { oxides }\end{array}$ & $\mathrm{R} 36160$ \\
\hline Condicionador de Porcelana & $\begin{array}{l}\text { Condicionador de Porcelana, } \\
\text { Dentsply DeTrey, GmbH, Germany }\end{array}$ & $10 \%$ hydrofluoric acid & $729554 \mathrm{E}$ \\
\hline Variolink II base & Ivoclar-Vivadent & $\begin{array}{l}\text { Bis-GMA, urethane dimethacrylate, triethylene } \\
\text { glycol dimethacrylate. barium glass, ytterbium } \\
\text { trifluoride, Ba-Al-fluorosilicate glass, spheroid } \\
\text { mixed, oxide, catalysts, stabilizers, pigments }\end{array}$ & $\mathrm{R} 43648$ \\
\cline { 2 - 4 } Variolink II catalyst & Ivoclar-Vivadent & $\begin{array}{l}\text { Alcohol solution of silane methacrylate, } \\
\text { phosphoric acidmethacrylate and sulphide } \\
\text { methacrylate }\end{array}$ & $\mathrm{R} 59556$ \\
\hline Monobond Plus & Ivoclar-Vivadent & \multicolumn{2}{|l}{} \\
\hline
\end{tabular}

Table 1. Brand names, manufacturers, chemical compositions and batch numbers of the materials used in the present study. Abbreviations. Bis-GMA: bisphenol A-glycidyl methacrylate.

and microshear bond testing ${ }^{3,4,10}$. The purpose of the present study was to evaluate, using a different method of tensile strength testing, the bond strength between resin cement and lithium disilicate ceramic that had been subjected to different surface treatments, including the Nd:YAG laser and Er:YAG lasers, in the presence or absence of a graphite surface coating. The null hypothesis tested was that laser irradiation and graphite coating of the ceramic surface have no effect on the bond strength between resin cement and lithium disilicate ceramic.

\section{Materials and Methods}

Specimen preparation. One hundred and seventy lithium disilicate truncated cones (IPS e.max Press; Ivoclar-Vivadent, Schaan, Lichtenstein) were fabricated using a lost-wax technique. The low contraction wax (Renfert Geo; Renfert GmbH, Hilzingen, Germany) was poured into a 4-mm thick metal split-mold with a 2-mm diameter wide base and a $4-\mathrm{mm}$ diameter wide top surface ${ }^{14}$. The specimens were heat-pressed according to the manufacturer's instructions (Table 1).

The pressed ceramic specimens were wet-polished with 600-grit silicon carbide paper in a circular polisher (DP-10; Panambra, São Paulo, SP, Brazil) using running water as coolant, and cleaned ultrasonically in distilled water for $5 \mathrm{~min}$. The polished specimens were allocated to five experimental groups $(\mathrm{N}=34$; Table 1$)$ :

1. Control. Each specimen was etched with HF ( $60 \mathrm{sec})$, rinsed with water spray for $60 \mathrm{sec}$, silanized with Monobond Plus (Ivoclar-Vivadent) for $60 \mathrm{sec}$ and air-dried.

2. Er:YAG laser. Each specimen was irradiated using a Er:YAG laser (Key Laser 3; KaVo Kerr, Washington, DC, USA) with $200 \mathrm{~mJ}$ energy, using a pulse repetition rate set at $10 \mathrm{pps}, 2.94 \mu \mathrm{m}$ wavelength and at $12 \mathrm{~mm}$ away from the specimen surface with water spray cooling $(5 \mathrm{sec})$. The irradiated ceramic surfaces were then etched with HF $(60 \mathrm{sec})$, rinsed with water spray $(60 \mathrm{sec})$, silanized and air-dried.

3. Graphite + Er:YAG laser. Each surface was graphite-coated by rubbing graphite lead perpendicular to the surface prior to Er:YAG laser irradiation using the same parameters described in II. The graphite-and-laser-treated specimen was etched with HF $(60 \mathrm{sec})$, rinsed with water spray $(60 \mathrm{sec})$, silanized and air-dried.

4. Nd:YAG laser: Each specimen was irradiated using a Nd:YAG laser (PulseMaster 600 IQ; American Dental Technologies Inc., Corpus Christi, TX, USA) with $120 \mathrm{~mJ}$ energy. The pulse repetition rate was set at 15 pps and a $320 \mu \mathrm{m}$ diameter laser optical fiber was placed in contact with the specimen surface for $1 \mathrm{~min}$ without water spray. The irradiated ceramic surfaces were then etched with HF $(60 \mathrm{sec})$, rinsed with water spray $(60 \mathrm{sec})$, silanized and air-dried.

5. Graphite + Nd:YAG laser: Each specimen surface was coated with graphite prior to Nd:YAG laser irradiation using the same parameters described in II. The graphite-and laser-treated-specimens were then etched with HF $(60 \mathrm{sec})$, rinsed with water spray $(60 \mathrm{sec})$, silanized and air-dried.

Surface analysis. Two specimens from each group were employed for qualitative analysis of the treated surface. Each specimen was sputtered-coated with gold-palladium and examined using a scanning electron microscope (SEM; Inspect S50, FEI Company, Hillsboro, OR, USA) at different magnifications. Two additional specimens from each group were evaluated using a digital optical profilometer (Wyko NT 1100; Veeco, Plainview, NY, USA). Images were analyzed with the Vision v3.60 software (Veeco) for the arithmetic mean value of surface roughness $\left(\mathrm{R}_{\mathrm{a}}\right)$. Measurement of surface roughness was performed at a magnification of 20.5X on two areas of each specimen (center and periphery).

Bonding procedures. The other 150 specimens $(\mathrm{N}=15)$ were bonded (two truncated cones per bonding assembly) at the bases with a dual-cured resin cement (Variolink II; Ivoclar-Vivadent) (Fig. 1). The resin cement was light-cured for $40 \mathrm{sec}$ using a light-emitting diode-type curing unit (Radii-Cal LED; SDI, Bayswater, Victoria, Australia).

Thermomechanical aging. The bonded specimens were subjected to thermomechanical challenge that consisted of 24,000 mechanical cycles $(30 \mathrm{~N}$ load at $4 \mathrm{~Hz})$ and 1,000 thermal cycles $(30 \mathrm{sec}$ dwell-time in each water bath with temperatures maintained at $5{ }^{\circ} \mathrm{C}, 37^{\circ} \mathrm{C}$ and $55^{\circ} \mathrm{C}$, respectively). Aging was conducted simultaneously in a thermomechanical cycler (Model ER-37000; ERIOS, São Paulo, Brazil). 

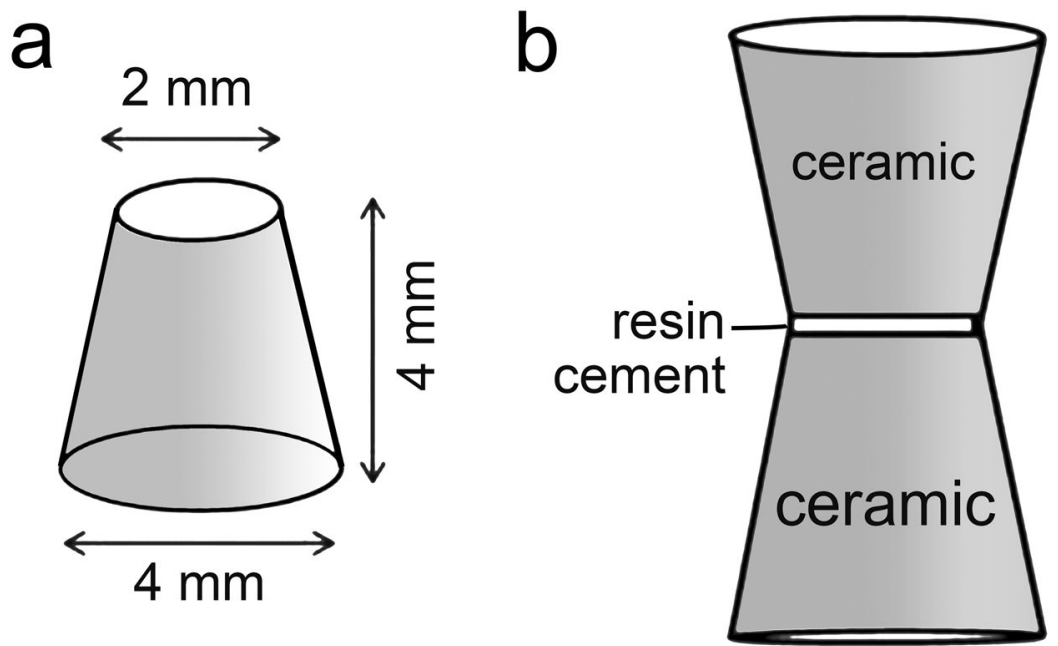

Figure 1. Specimen dimensions. (a) Lithium disilicate truncated cone. (b) Hourglass-shaped specimen.

Tensile bond strength. Bond strength was evaluated in a universal testing machine (model DI-1000; EMIC São José dos Pinhais, Brazil) by attaching a specimen to a custom-made device (Fig. 2), using a $10 \mathrm{~kg}$ load cell at a cross-head speed of $1 \mathrm{~mm} / \mathrm{min}$. Loading was performed in tension until failure. Results of tensile testing (in MPa) were statistically analyzed using one-factor analysis of variance (ANOVA) after affirming that the normality and equal variance assumptions of the data were not violated. The Dunnett test was employed for post-hoc comparison of the four experimental treatment groups with the HF control. In addition, two-factor ANOVA was used to examine the effects of "laser" and "graphite coating" on the tensile strength of resin cement to lithium disilicate ceramic (the control group was excluded from this analysis). Post-hoc pairwise comparisons were performed using the Tukey test. For all analyses, statistical significance was pre-set at $\alpha=0.05$. Two representative specimens from each group with bond strength close to the respective mean value were employed for qualitative analysis of the fractured interface. The specimens were sputtered-coated with gold-palladium and examined using SEM at different magnifications.

\section{Results}

SEM of pre-bonded, surface-treated specimens. Scanning electron microscopy images (left column, Fig. 3) showed grooves and cracks in specimens that had been treated with Graphite + Er:YAG laser (Fig. 3e) and Nd:YAG laser treatments (Fig. 3g). The Graphite + Nd:YAG laser group (Fig. 3i) showed craters and surface modification in the ceramic when compared to all the other groups.

Roughness parameters (arithmetic means of all peaks and valleys) of the center and periphery of the surface-treated specimens are reported in Table 2. Higher surface roughness was achieved after the lithium disilicate specimens were subjected to Er:YAG laser treatment (Fig. 3d), while lower surface roughness was seen after specimens received Graphite + Nd:YAG laser treatment (Fig. 3j). The profilometry images (right column, Fig. 3) complemented what the SEM observations.

Tensile bond strength. Descriptive statistics (means and standard deviations) of the tensile testing results are shown in Table 2. There was no pre-test failure when the hourglass-shaped bonded specimen configuration was employed.

Group 2 (Er:YAG laser) showed the highest tensile strength $(27.5 \pm 7.1 \mathrm{MPa})$. Graphite coating reduced the tensile strengths of the two laser-irradiated groups, especially for Group V (Graphite + Nd:YAG laser). The Dunnett test was used to compare the Control group with the other four experimental groups. Only the tensile strength of Group 2 (Er:YAG laser) was statistically different $(\mathrm{p}=0.00002)$ from the Control (Group 1) (Table 3).

The effects of Nd:YAG/Er:YAG laser irradiation, and the presence/absence of graphite coating on the bond strength between lithium disilicate and resin cement were analyzed by two-way ANOVA. Both the factors "laser" $(\mathrm{p}=0.00)$ and "graphite coating" $(\mathrm{p}=0.00)$ significantly affected tensile strength of the resin cement to the lithium disilicate ceramic. The interaction of thoese two factors was not statistically significant $(\mathrm{p}=0.059)$. Post-hoc Tukey test showed that Er:YAG laser treatment (mean value: $21.7 \mathrm{MPa}$ ) produced higher tensile bond strength $(\mathrm{p}<0.05)$ than Nd:YAG laser treatment (mean value: $12.9 \mathrm{MPa})$, while groups with graphite coating (mean value: $11.5 \mathrm{MPa})$ produced lower tensile strength $(\mathrm{p}<0.05)$ when compared to the groups without graphite coating (mean value: $23.8 \mathrm{MPa}$ ).

Analysis of fractured interface. Microscope fracture analysis showed that most of the failures were adhesive and cohesive within the cement for all groups except for the Graphite $+\mathrm{Nd}$ :YAG laser group, in which only adhesive failure was observed. 


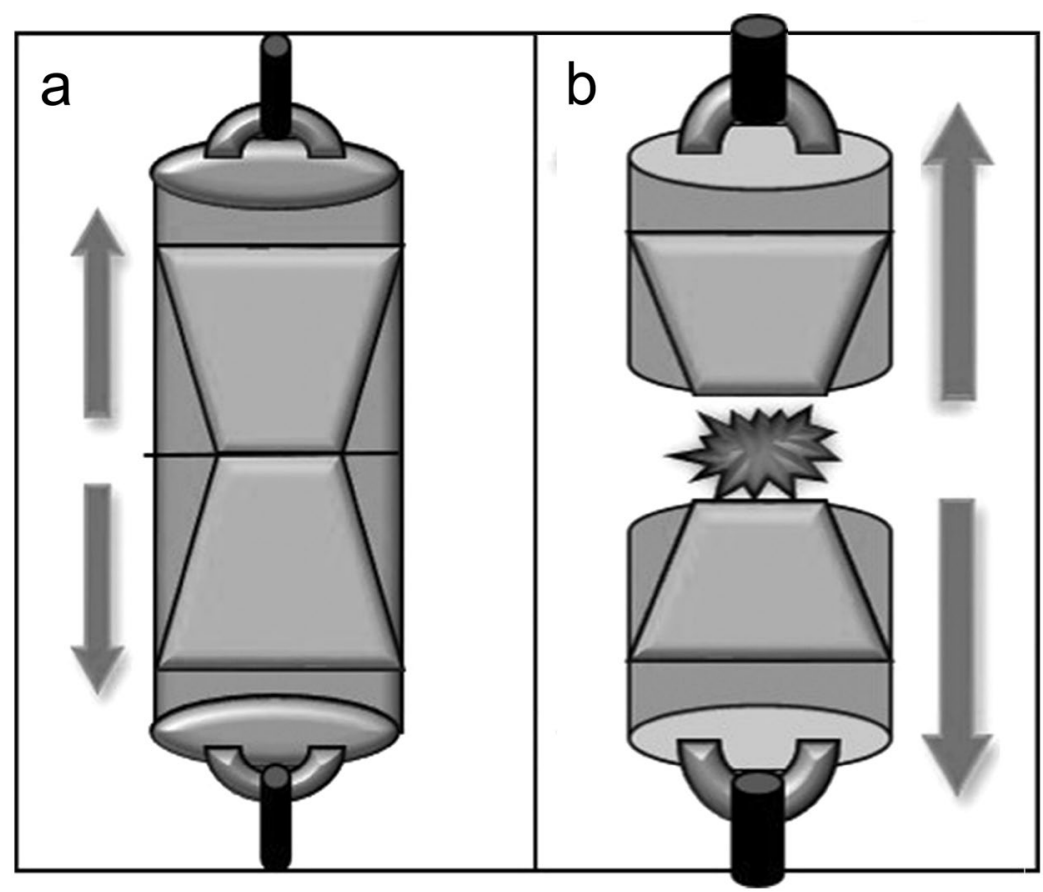

Figure 2. Schematic of the tensile test. (a) Before testing. (b) After stressing the bonded assembly to failure.

\section{Discussion}

The results of the present study indicate that the adjunctive use of laser surface treatment improves the tensile strength of resin cement to lithium disilicate, while pre-coating the ceramic surface with graphite prior to laser irradiation and HF etching adversely affects the tensile strength between the cement and ceramic. Thus, the null hypothesis that laser irradiation and graphite coating of the ceramic surface have no effect on the bond strength between resin cement and lithium disilicate ceramic has to be rejected. Thermomechanical cycling was employed as a form of artificial aging in the present study to incorporate an element of durability into the testing of the resin-ceramic bonds. There was no comparison of tensile strengths before and after aging because the study objective was to evaluate differences in bond strength among different surface treatments after aging.

Previous studies evaluated resin-ceramic bond strength using shear, micro-shear or micro-tensile testing techniques ${ }^{3,4,10,12}$. Stress induction during specimen preparation for mechanical testing, as well as the different shapes and geometry of the prepared specimens may induce interference to the testing results, leading researchers to discordant conclusions. In their design of the microtensile test, Sano et al. opined that the tensile strength is inversely proportional to the size of tested surface, and that adhesive failure predominantly occurs if the cross-sectional surface area is approximately $1 \mathrm{~mm}^{2,15,16}$. However, the "stick" or "beam" version of the microtensile test is not a practical test for evaluating bonding to ceramics. This is because stress induction during specimen results in many premature failures prior to testing ${ }^{17}$. The 'trimmed' version of the microtensile test requires the researcher to prepare hourglass-shaped specimens ${ }^{18}$. When trimming is not carefully performed, interfacial defects may easily be introduced that precipitates crack propagation during tensile loading of the specimen, eventually resulting in premature failure and much reduced interfacial strength. The shear test is another simple mechanical test to perform, but there is difficulty in placing the specimen in a defined area and maintaining that position during loading, which results in a lot of friction ${ }^{19}$. Both the micro-tensile and shear tests may generate unrealistic results. Because of the difficulty in obtaining realistic bond strength data between resin cements and ceramics, the present study adopted a method that combines the advantages of tensile and micro-tensile tests by using small bond surface diameter $(2 \mathrm{~mm})$ and avoiding stress induction during specimen preparation. The test yielded acceptable results with no premature failures.

Many studies have reported ways to improve the bond strength between resin cement and ceramics by creating micro-retentions or other modifications on the ceramic surface ${ }^{4,7,20-23}$. The present study shows that Er:YAG laser irradiation followed by HF etching increases the bond strength of lithium disilicate ceramics to resin cement when compared to the control group (Table 3). These findings are contrary to those reported by Foxton et al. ${ }^{24}$ and Akyil et al. ${ }^{25}$. The difference may be explained by the method employed for mechanical testing. Foxton et al. ${ }^{24}$ employed the shear test while Akyil et al. ${ }^{25}$ used the micro-tensile test to evaluate the strength of the resin-ceramic bond. The Er:YAG laser irradiation parameters employed were also different. Different power settings have been employed in the literature for laser irradiation of ceramic surfaces $6,7,9,10,12,24,26,27$. The power setting adopted in the present study was based on the one used by Cavalcanti et al. ${ }^{12}$, which involved a lower power setting $(220 \mathrm{~mJ})$ and constant water cooling.

The Nd:YAG laser surface treatment demonstrated worse results than the Er:YAG laser group and the results were not significantly different from the HF control group. When specimens were analyzed for surface roughness, those derived from the Er:YAG laser group had higher $\mathrm{R}_{\mathrm{a}}$ values, followed by specimens from the Nd:YAG laser 


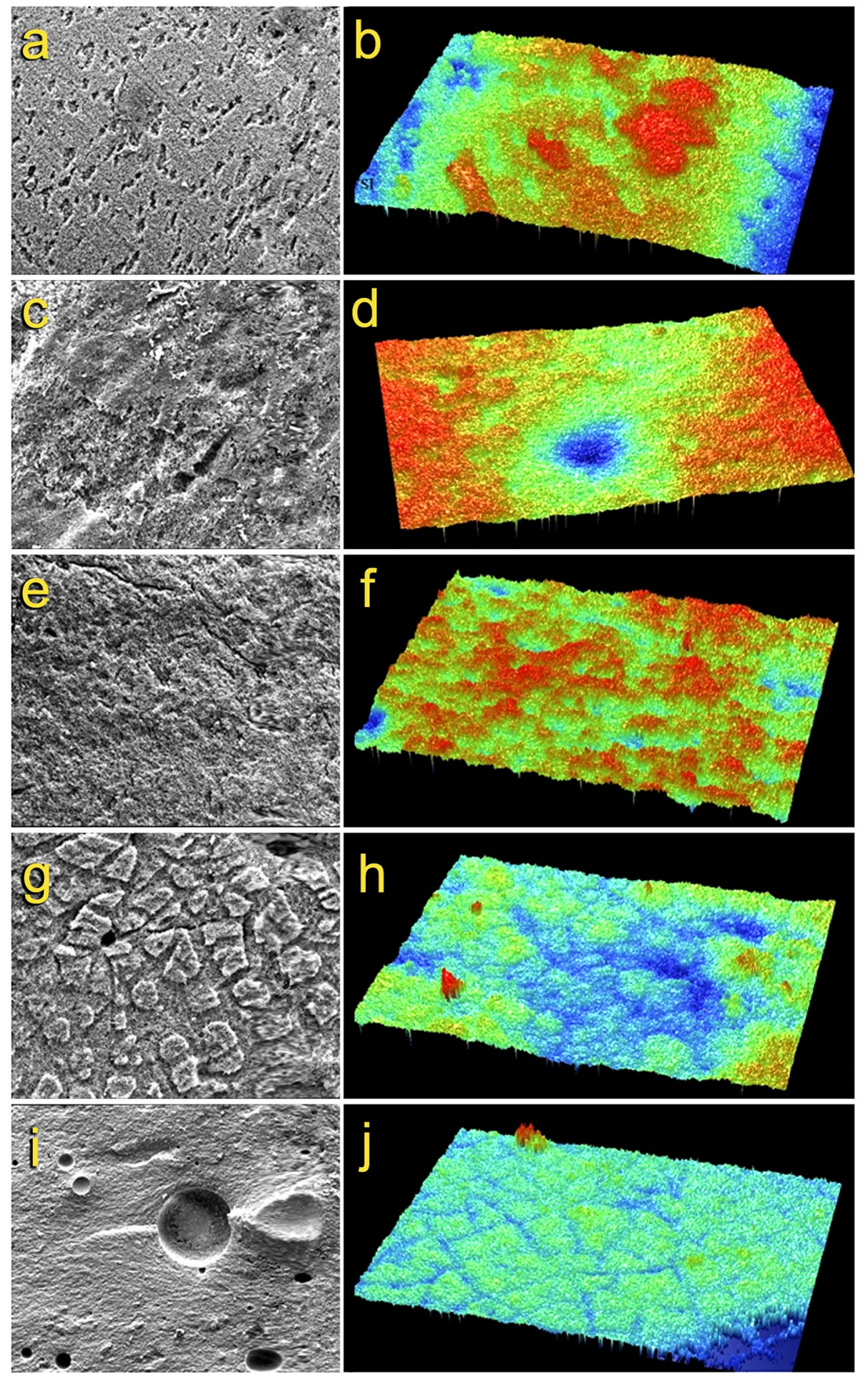

Figure 3. Scanning electron microscopy (SEM; left column) and 3-D profilometry images (20.5 $\times$; right column) of lithium disilicate specimens after different surface treatments. (a) SEM $(1000 \times)$ and (b) profilometry images of the hydrofluoric acid-etched control group. (c) SEM $(1000 \times)$ and (d) profilometry images of the Er:YAG laser group. (e) SEM $(1000 \times)$ and (f) profilometry images of the Graphite + Er:YAG laser group. (g) SEM $(1000 \times)$ and (h) profilometry images of the Nd:YAG laser group. (i) SEM $(500 \times)$ and $(\mathbf{j})$ profilometry images of the Graphite $+\mathrm{Nd}$ :YAG laser group. The lower SEM magnification enabled visualization of the craters scattered across the treated ceramic surface.

group (Table 2). These findings were different from those reported by Kara et al. ${ }^{26}$, who concluded that there was no significant difference between Nd:YAG laser and Er:YAG laser irradiation on the roughness of lithium disilicate surfaces. 


\begin{tabular}{|l|l|l|l|l|l|}
\hline Groups & $\begin{array}{l}\text { Means (standard } \\
\text { deviation) }\end{array}$ & Minimum & Maximum & $\begin{array}{l}\text { Roughness Surface } \\
\text { (center) }\end{array}$ & $\begin{array}{l}\text { Roughness Surface } \\
\text { (periphery) }\end{array}$ \\
\hline Control & $14.3(4.4)$ & 8.2 & 22.18 & 2.64 & 1.39 \\
\hline Er:YAG laser & $27.5(7.1)$ & 8.9 & 32.7 & 3.48 & 2.14 \\
\hline Graphite + Er:YAG laser & $12.1(3.5)$ & 8.4 & 18.8 & 1.29 & 1.16 \\
\hline Nd:YAG laser & $17.7(4.9)$ & 11.8 & 17.4 & 2.69 & 1.46 \\
\hline Graphite + Nd:YAG laser & $7.7(3.6)$ & 3.1 & 15.5 & 0.91 & 0.86 \\
\hline
\end{tabular}

Table 2. Mean (standard deviations) tensile bond strength values (in $M P a)$ and surface roughness results $\left(\mathrm{R}_{\mathrm{a}}\right.$, in $\left.\mu \mathrm{m}\right)$ for the control and experimental groups.

\begin{tabular}{|l|l|}
\hline Compared with Control group & p Value \\
\hline Er:YAG laser & $0.00002^{*}$ \\
\hline Graphite + Er:YAG laser & 0.602 \\
\hline Nd:YAG laser & 0.076 \\
\hline Graphite + Nd:YAG laser & 0.999 \\
\hline
\end{tabular}

Table 3. Dunnett test comparing the laser-irradiated and graphite-coated groups with the control group. *Significantly different $(\mathrm{p}<0.05)$.

Studies employing surface coating with graphite prior to laser irradiation suggested that such a coating increases energy absorption, which in turn, improves the efficacy of ceramic surface modification by the laser,12,13,24. Results derived from the present study showed that placement of a graphite coating adversely affected the efficacy of both lasers. The lower surface roughness that resulted from the presence of a graphite coating was complementary to the tensile testing results. In the future, additional studies are necessary to investigate the efficacy of the graphite coating technique, because all of the previous studies evaluated laser irradiation with graphite coating in all groups.

Scanning electron microscopy showed that the use of Er:YAG laser irradiation followed by HF etching modified the lithium disilicate surface. It appears that the period of laser application $(5 \mathrm{sec})$ has to be extended, because morphologic examiniation revealed some locations on the laser-treated surface that were similar to the control group. The Graphite + Er:YAG laser and Nd:YAG laser groups showed reduction of surface roughness; however, the micro-structures were not modified and appeared similar to the HF control group. Nevertheless, more research comparing different resin cements is warranted.

\section{Conclusions}

Within the limits of the study, the following conclusions may be drawn:

1. The hourglass-shaped specimen design is effective for measuring resin-ceramic bond strength under tension by completely eliminating pre-test failure.

2. The Er:YAG laser produces higher bond strength than the other surface treatment regimens when it is used adjunctively with hydrofluoric acid. Such a technique may be considered during bonding of resin cement to lithium disilicate ceramic.

3. Surface coating with graphite prior to laser irradiation does not increase in bond strength between the resin cement and ceramic.

\section{References}

1. Kosmac, T., Oblak, C., Jevnikar, P., Funduk, N. \& Marion, L. The effect of surface grinding and sandblasting on flexural strength and reliability of Y-TZP zirconia ceramic. Dent. Mater. 15, 426-433 (1999).

2. Kitayama, S. et al. Internal coating of zirconia restoration with silica-based ceramic improves bonding of resin cement to dental zirconia ceramic. Biomed. Mater. Eng. 20, 77-87 (2010).

3. Guarda, G. B. et al. Effects of surface treatments, thermocycling, and cyclic loading on the bond strength of a resin cement bonded to a lithium disilicate glass ceramic. Oper. Dent. 38, 208-217 (2013).

4. Liu, L., Liu, S., Song, X., Zhu, Q. \& Zhang, W. Effect of Nd: YAG laser irradiation on surface properties and bond strength of zirconia ceramics. Lasers Med. Sci. 30, 627-634 (2015).

5. Fabianelli, A. et al. The effect of different surface treatments on bond strength between leucite reinforced feldspathic ceramic and composite resin. J. Dent. 38, 39-43 (2010).

6. Demir, N., Subaşi, M. G. \& Ozturk, A. N. Surface roughness and morphologic changes of zirconia following different surface treatments. Photomed. Laser Surg. 30, 339-345 (2012).

7. Dilber, E., Yavuz, T., Kara, H. B. \& Ozturk, N. A. Comparison of the effects of surface treatments on roughness of two ceramic systems. Photomed. Laser Surg. 30, 308-314 (2012).

8. Akın, H., Ozkurt, Z., Kırmalı, O., Kazazoglu, E. \& Ozdmir, A. K. Shear bond strength of resin cement to zirconia ceramic after aluminum oxide sandblasting and various laser treatments. Photomed. Laser Surg. 29, 797-802 (2011).

9. Usumez, A. et al. Bond strength of resin cement to zirconia ceramic with different surface treatments. Lasers Med. Sci. 28, 259-266 (2013). 
10. Gomes, A. L., Ramos, J. C., Santos-Del Riego, S., Montero, J. \& Albaladejo, A. Thermocycling effect on microshear bond strength to zirconia ceramic using Er:YAG and tribochemical silica coating as surface conditioning. Lasers Med. Sci. 30, 787-795 (2015).

11. Da Silveira, B. L. et al. Micro-tensile bond strength between a resin cement and an aluminous ceramic treated with Nd:YAG laser, Rocatec System, or aluminum oxide sandblasting. Photomed. Laser Surg. 23, 543-548 (2005).

12. Cavalcanti, A. N. et al. Bond strength of resin cements to a zirconia ceramic with different surface treatments. Oper. Dent. 34, 280-287 (2009).

13. Cavalcanti, A. N. et al. Evaluation of the surface roughness and morphologic features of Y-TZP ceramics after different surface treatments. Photomed. Laser Surg. 27, 473-479 (2009).

14. Pucci, C. R. et al. Evaluation of the cohesive strength between resin composite and light-curing characterizing materials. J. Adhes. Dent. 14, 69-73 (2012).

15. Sano, H., Ciucchi, B., Matthews, W. G. \& Pashley, D. H. Tensile properties of mineralized and demineralized human and bovine dentin. J. Dent. Res. 73, 1205-1211 (1994).

16. Sano, H. et al. Relationship between surface area for adhesion and tensile bond strength-evaluation of a micro-tensile bond test. Dent. Mater. 10, 236-240 (1994).

17. Van Meerbeek, B. et al. Relationship between bond-strength tests and clinical outcomes. Dent. Mater. 26, e100-121 (2010).

18. Pashley, D. H. et al. The microtensile bond test: a review. J. Adhes. Dent. 1, 299-309 (1999).

19. Dentistry-Testing of adhesion to tooth structure. International Standards Organization, Switzerland. ISO/TS 11405:2015. (2015).

20. Vanderlei, A., Bottino, M. \& Valandro, L. Evaluation of resin bond strength to yttria-stabilized tetragonal zirconia and framework marginal fit: Comparison of different surface conditionings. Oper. Dent. 39, 50-63 (2014)

21. Carvalho, R. F., Martins, M. E., de Queiroz, J. R., Leite, F. P. \& Ozcan, M. Influence of silane heat treatment on bond strength of resin cement to a feldspathic ceramic. Dent. Mater. J. 30, 392-397 (2011)

22. Ozcan, M., Nijhuis, H. \& Valandro, L. F. Effect of various surface conditioning methods on the adhesion of dual-cure resin cement with MDP functional monomer to zirconia after thermal aging. Dent. Mater. J. 27, 99-104 (2008).

23. Nagai, T., Kawamoto, Y., Kakehashi, Y. \& Matsumura, H. Adhesive bonding of a lithium disilicate ceramic material with resin-based luting agents. J. Oral. Rehabil. 32, 598-605 (2005).

24. Foxton, R. M. et al. Durability or resin cement bond to aluminum oxide and zirconia ceramic after air abrasion and laser treatment. J. Prosthodont. 20, 84-92 (2011).

25. Akyıl, M. Ş., Yılmaz, A., Bayındır, F. \& Duymuş, Z. Y. Microtensile bond strength of resin cement to a feldspathic ceramic. Photomed. Laser Surg. 29, 197-203 (2011).

26. Kara, H. B., Dilber, E., Koc, O., Ozturk, A. N. \& Bulbul, M. Effect of different surface treatments on roughness of IPS Empress 2 ceramic. Lasers Med. Sci. 27, 267-272 (2012).

27. Yavuz, T., Dilber, E., Kara, H. B., Tuncdemir, A. R. \& Ozturk, A. N. Effects of different surface treatments on shear bond strength in two different ceramic systems. Lasers Med. Sci. 28, 1233-1239 (2013).

\section{Acknowledgements}

The authors thank the support from Fapesp Proc 2013/02953-5 and 2012/08443-6, and grant 2015QNRC001 from Young Elite Scientist Sponsorship Program by CAST.

\section{Author Contributions}

F.A.F. and R.M.D. performed the experiments and analytical part of the study and wrote the manuscript. F.R.T., L.N.N. and C.R.P. supervised the project and edited the manuscript. All authors reviewed the manuscript.

\section{Additional Information}

Competing Interests: The authors declare that they have no competing interests.

Publisher's note: Springer Nature remains neutral with regard to jurisdictional claims in published maps and institutional affiliations.

(i) Open Access This article is licensed under a Creative Commons Attribution 4.0 International

License, which permits use, sharing, adaptation, distribution and reproduction in any medium or format, as long as you give appropriate credit to the original author(s) and the source, provide a link to the Creative Commons license, and indicate if changes were made. The images or other third party material in this article are included in the article's Creative Commons license, unless indicated otherwise in a credit line to the material. If material is not included in the article's Creative Commons license and your intended use is not permitted by statutory regulation or exceeds the permitted use, you will need to obtain permission directly from the copyright holder. To view a copy of this license, visit http://creativecommons.org/licenses/by/4.0/.

(C) The Author(s) 2017 